\title{
Phytopathology at the Wageningen Agricultural University
}

\author{
J. C. Zadoks
}

Department of Phytopathology, Binnenhaven 9, 6709 PD Wageningen, Netherlands

\begin{abstract}
Contributions of the Department of Phytopathology, Agricultural University, Wageningen, Netherlands, to the science of phytopathology are described in rough outline. They cover the areas 'ecology of soil-borne fungi', 'epidemiology', 'phytopharmacy', and 'physiology of host-parasite interactions'. The research contributes to the advance of science, supports teaching duties, and produces practical applications.
\end{abstract}

\section{Introduction}

During the past 25 years, phytopathology as a world-embracing science developed by leaps and bounds, gaining both in width and depth. The volume of Dutch science is but one per cent of the world's total volume of science, but the conclusion that Dutch phytopathology progressed proportionally, which is at a snail's pace, would be unjustified. Dutch phytopathologists can be found in the forefront of their science.

The point will be illustrated by recent developments in the Department of Phytopathology of the Agricultural University, in the full awareness that focussing on one institution only does great injustice to many other meritorious institutions in the Netherlands.

Two baseline papers facilitate this narrative, one in commemoration of the great contributions of Professor A. J. P. Oort to Dutch phytopathology (Zadoks \& Dekker, 1969) and another one explaining the teaching programme of the department (Zadoks, 1974). Oort set out two lines toward the future, which - in present-day terminology - could be named 'physiology of host-parasite interaction' and 'epidemiology'. He was succeeded by J. Dekker and J. C. Zadoks, who further developed these lines, whereas colleagues developed research in the 'ecology of soil-borne fungi' and in 'phytopharmacy'.

\section{Research developments}

\section{Dutch crop protection}

The economic importance of crop protection in the Netherlands is tremendous ( $\mathrm{Za}-$ doks, 1984b), and as crop protection in the Netherlands is an old activity, its organi- 
zation is complex. Here, it is enough to state that there are a Plant Protection Service (PD) for regulatory activities, a Research Institute for Plant Protection (IPO) for applied research, several research stations and an extension service for the implementation of research results in practice, and many other institutions spending part of their time on crop protection. Teaching at the university level is offered at the Agricultural University in Wageningen and at the Phytopathological Laboratory 'Willie Commelin Scholten' at Baarn. Whereas the latter institution, serving several universities, mainly offers teaching and research in phytopathology in a narrow sense, the Agricultural University has departments for Entomology, Herbology, Nematology, Phytopathology, and Virology.

A traditional task of universities in the Netherlands is fundamental research, aimed at deepening scientific insight rather than at solving practical problems. The emphasis on fundamental research, imposed by the stratified structure of research and extension in the Netherlands, easily leads to isolation from practice. Such isolation is resented by several scientists. In recent times, political objections have been raised against such isolation, politicians and students demanding more 'relevance' in research.

The Department of Phytopathology has always steered its own course, striving to be at the forefront of international science, but with an open eye for practical problems within the Netherlands, and in the tropics. The particular blend resulting from a compromise between two seemingly opposite orientations has attracted many a positive comment from foreign visitors. The blend of fundamental and practiceoriented approaches lured many a native student into phytopathological studies.

\section{Ecology of soil-borne fungi}

Research topics were pasteurization of greenhouse soil and the effects of heat treatments of soil, and various aspects of the use of benzimidazoles. Pasteurization research led to a 'thermometer' (Fig. 1) with the lethal temperatures of pathogenic and saprophytic soil fungi. It is now widely used in horticulture as an explanatory and predictive tool. The role of antagonists in the colonization of pasteurized soil was clearly recognized (Bollen, 1974). In the late 1960s, the methylbromide era, practice did not yet accept pasteurization, though it recognized its effectiveness.

Benzimidazoles and related compounds were studied in detail in the 1970s. In vitro and in situ activity of these compounds were closely linked, which permitted the prediction of effectiveness of these compounds. When used in chemotaxonomy, their activity spectrum was in line with the present system of classification of fungi (deuteromycetes). The effect of benzimidazoles on microbial antagonism of pathogens was established. The results helped to understand unexpected phenomena observed in chemical disease control, such as the change of dominance among pathogens after application of these fungicides (Bollen, 1985).

The topic 'heat treatment of soils' got new impetus in the 1980s, the post-methylbromide era, when the use of this compound was restricted for environmental reasons. The pattern of recolonization in heat-treated soils became known, but 'supervised' recolonization still meets with problems. Studies on the fate of pathogens during compostation of infested crop residues revealed that most of the pathogens 


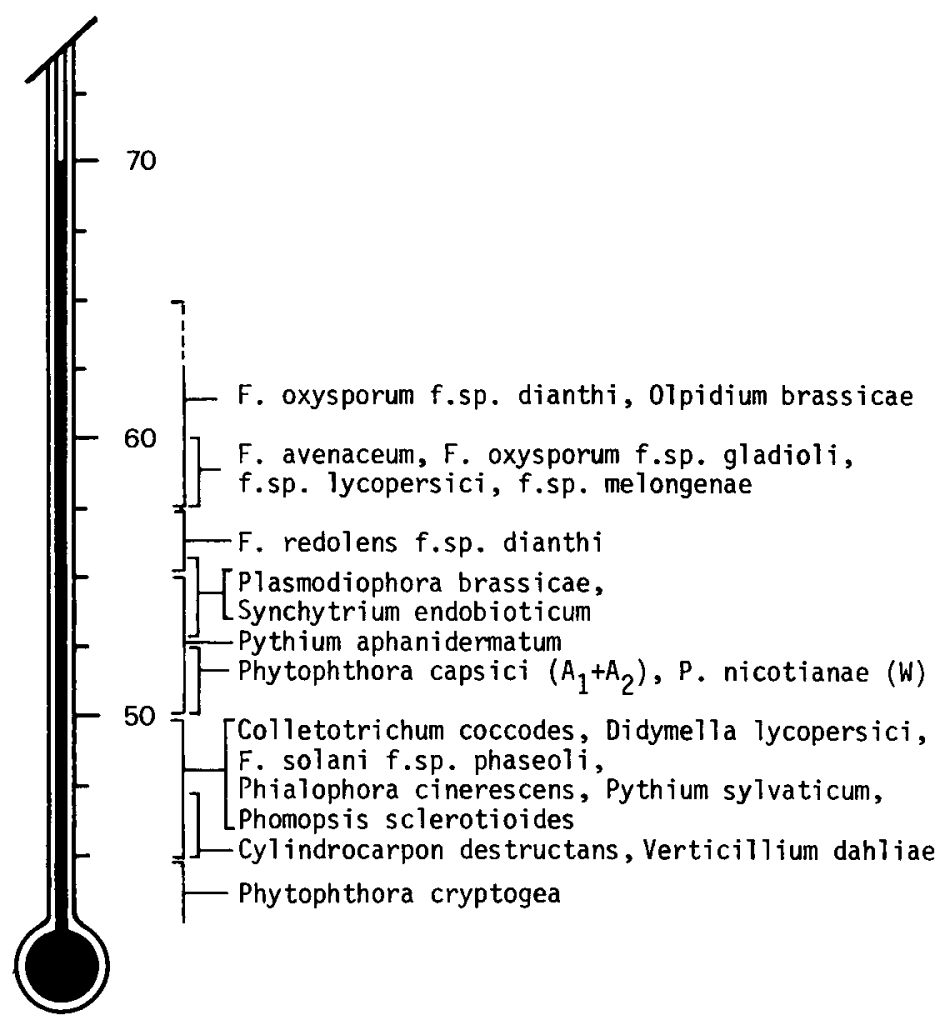

Fig. 1. The 'thermometer' for the effect of heat treatment of greenhouse soils on parasitic fungi.

were killed during the heat phase. These studies produced impulses toward commercial application. Heat treatment of recirculation fluid in greenhouses with hydroponics is under investigation presently.

Whereas the foregoing research was aimed at controlling noxious fungi by mild methods, another line of research is directed toward factors inhibiting beneficial fungi. These are the mycorrhizal fungi of many crops and forest trees (Limonard \& Smits, 1985). Modern agriculture with its high fertilizer inputs does not favour mycorrhizal fungi of arable crops (Ruissen, 1982). But worse is the effect of 'acid rain' on mycorrhizal fungi of forest trees. In our Department much attention is being paid now to the problem of deterioration of mycorrhizal fungi and to explore the potential use of mycorrhizal fungi in reforestation, both in the Netherlands and in the tropics. The future of our forests may depend on such research.

\section{Epidemiology}

Epidemiology was recognized as a (sub)discipline in its own rights since 1963 (Zadoks and Koster, 1976). Oort's interest had led already to a gene-for-gene hypothe- 


\section{J. C. ZADOKS}

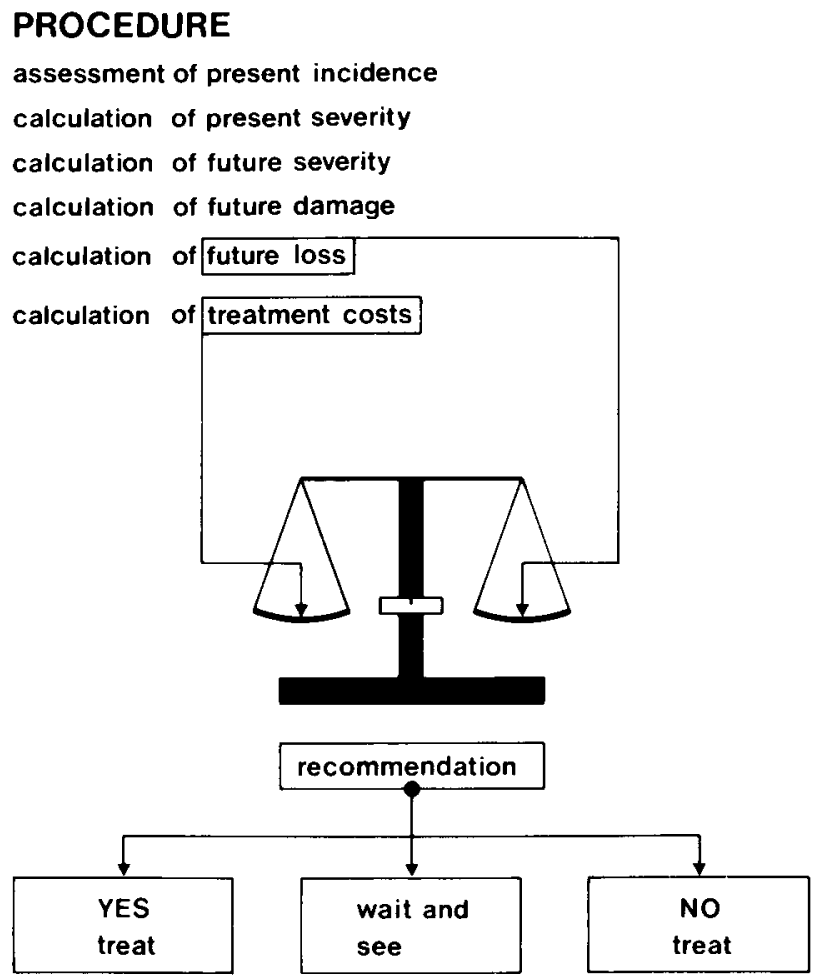

Fig. 2. Economics in the chain of decisions made by EPIPRE. From Zadoks (1984).

sis before that concept existed (Oort, 1944), which did not receive the recognition it deserved, as it was published in Dutch and during World War II. His continued interest stimulated a number of students to do research in epidemiology, a sequence carried on until today. The emphasis shifted gradually from mycological and meteorological aspects to quantitative phenomena, crop loss, and selection for resistance breeding. These various aspects were systematically arranged in a text book ( $\mathrm{Za}$ doks \& Schein, 1979) sponsored by two universities, the Wageningen Agricultural University and the Pennsylvania State University. This book was a kind of fingerexercise for a new venture, the development of a computerized disease and pest management system for wheat named EPIPRE. As a conjunction of the planets, several developments fell in line: (1) the availability of a full-fledged epidemiological theory; (2) the availability of adequate computers; (3) the commercialization of systemic fungicides effective against major cereal diseases; and (4) the rising fear for ill-effects if these were to be applied on arable crops, that is, on large acreages. The conjunction led to a project proposal in 1976 (Rabbinge \& Rijsdijk, 1984; Zadoks, 1984a), which eventually changed teaching, research and practice.

EPIPRE has had a positive effect on Dutch and European phytopathological research, and it should be noted that the considerable attention paid to the EPIPRE 
system by farmers, scientists and politicians has influenced general recommendation. Dutch farmers did not turn, in large numbers, to high-input cropping of wheat with many routine sprays. With only one or two routine sprays, Dutch cereal farming cannot be classified as very intensive, in comparison to the intensive wheat production systems in the United Kingdom and Western Germany. In those systems at least ten sprays are being applied to control pests and diseases (Reinink, 1986). EPIPRE is used in the Netherlands, Belgium and Switzerland, to a limited extent in the United Kingdom, France, Germany and Sweden, and - in adapted form - in Norway. Incorporation of economic considerations in the 'decision support system', as EPIPRE might be called, was part of its success.

Studies in disease management are being continued, for example in fire blight of pear. Bacterial diseases in general receive more attention nowadays, with survival of plant-pathogenic bacteria as a focal point. Practice-oriented epidemiological research attracts many students. They assisted in studies, now completed, on the epidemiology of powdery mildew (Sphaerotheca pannosa) on roses (Frinking \& Scholte, 1983) and Spinach downy mildew (Peronospora farinosa) (Frinking et al., 1985). Students helped to start up new investigations in cabbage diseases (Mycosphaerella brassicicola and Xanthomonas campestris). Practical applications of the results are within reach.

\section{Phytopharmacy}

Disease control by systemic compounds is part of the broad area of phytopharmacy. Studies were initiated in 1951 by Oort, who established a Research Unit for Internal Therapy of Plants. This research unit concentrated on basic principles of disease control, the mode of action of systemic fungicides, the selective toxicity of fungicides, and the biochemistry of fungal resistance to fungicides.

The Department contributed to the unraveling of the 'mode of action' of benzimidazoles and other compounds. The fungicidal effect of carbendazim, one of the benzimidazoles, is based on its binding to tubulin, a subunit of the microtubules which constitue the major part of the cytoskeleton. Resistance to carbendazim may be due to a mutation in one gene only (van Tuyl, 1977), leading to reduced affinity of fungal tubulin to carbendazim (Davidse \& Flach, 1977). Altered tubulin molecules assemble normally. Apparently, a very essential and - in the evolutionary sense - conservative protein can change when the survival of the organism is at stake. This work on benzimidazoles had a great impact on microtubule research in general (Davidse, 1986).

A fungus strain may possess a genetic factor mediating resistance against two or more toxicants, a phenomenon called cross resistance. However, in rare cases resistance against one fungicide may lead to an increased sensitivity to another one, related or unrelated, a phenomenon called negatively correlated cross resistance. In other instances, a mixture of two chemicals produces a toxic effect on a pathogen greater than the sum of the toxic effects of each chemical separately; this phenomenon is called synergism (Fig. 3). Both phenomena can be exploited to cope with fungicide resistance (de Waard, 1985). Recent work also involves monitoring of fungicide-resistant strains in various mildews, such as Erysiphe graminis on wheat (de 


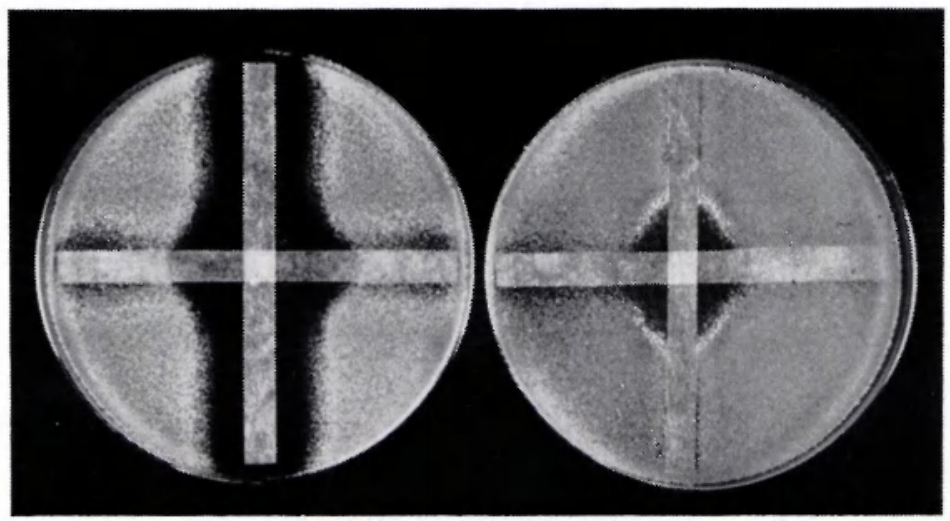

Fig. 3. Small experiments with big consequences. Interaction between fenarimol (in the vertical paper strip) and sodium orthovanadate (horizontal paper strip) to Penicillium italicum (grey in petri dishes). Reactions of a wild type (left) and a fenarimol-resistant strain (right); in the black areas the fungus was killed. From de Waard (1985).

Waard et al., 1986) and Sphaerotheca fuliginea on cucumber (Schepers, 1985). The combination of monitoring in fields and greenhouses with meticulous laboratory experiments may lead to a strategy of fungicide management. The objective is to maintain the susceptibility of fungal populations to the various fungicides and, in doing so, to extend the economic life of these fungicides by judicious combinations and alternations of active ingredients (Dekker, 1985). Such a strategy, especially in combination with sanitation, seems to be highly promising. A link with EPIPRElike decision support systems is to be expected in the future.

\section{Physiology of host-parasite interactions}

Around 1970 , much attention was drawn to the mysterious phytoalexins, antimicrobial compounds of low molecular weight produced by plants. Phytoalexins, induced by infecting pathogens (and other agents), were supposed to play a part in the first line of defense against infection. Though many papers were published, no major breakthrough appeared in Wageningen nor elsewhere in the world. Phytoalexins are a reality, their role is still somewhat uncertain, and any practical exploitation of these plant-generated substances is further than ever.

Another development drew worldwide attention too. When pathogenic fungus and host plant meet, they exchange signals. Somehow, the fungus must recognize the host as an attractive grazing ground, somehow the host must be able to detect the danger of being infected in order to activate its defense mechanism, and somehow the fungus must be able to overcome or mislead the host defenses. This is still a nebulous area of research, but a break-through is in reach now.

Early signals produced by the fungus were tentatively called elicitors, as they were supposed to elicit early defense reactions in the host, which was thought to have specific receptors for these elicitors. How to get these mysterious, hypothetical substances in hands? De Wit et al. $(1982,1985)$, working with Cladosporium ful- 


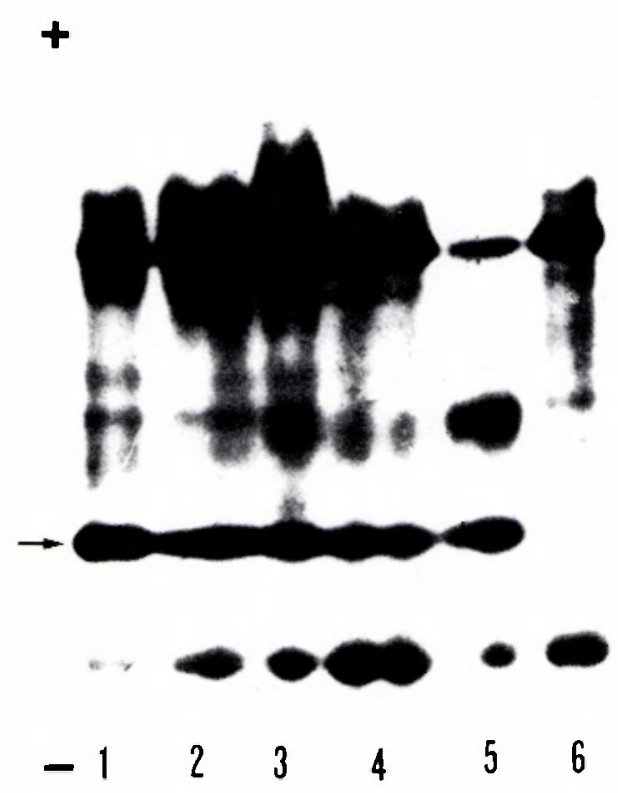

Fig. 4. Proteins, made visible by electrophoresis, in intercellular fluids from incompatible combinations ( 1 to 5) of tomato and Cladosporium fulvum genotypes. the arrow indicates the position of the necrosisinducing peptides. Only the compatible combination 6 (Sonatine/race 2.4.5.9) did not produce a necrosis-inducing peptide. From de Wit et al. (1985).

vum, the causal agent of tomato leaf mould, collected these putative elicitors from intercellular washing fluids of infected tomato leaves. The elicitors gave a race-specific response after injection into the intercellular space of tomato cultivars carrying a gene for resistance to $C$. fulvum. The gene-for-gene hypothesis is redesigned in molecular terms! One of the race-specific elicitors is a protein of low molecular weight, supposedly the product of a gene for avirulence.

The scientific significance of this result has found wide recognition. Practical applications are within reach. It is no longer necessary to test new breeding lines of tomatoes with living inoculum of various races; minute quantities of the fluid with the elicitors representing the various products of avirulence genes, injected into the leaf of a healthy plant, cause the same lesions as if the plant were inoculated by the actual fungal strains. World-wide testing and standardization of avirulence in the pathogen and resistance in the host comes within reach, simply by circulating a few test tubes with diagnostic fluid instead of the pathogenic fungi themselves, a method of great phytosanitary advantage.

Even more fantastic possibilities appear. If the products of the avirulence genes in the pathogen were known, we could use these to isolate and identify the genes for resistance in the host, clone them, and insert them into other tomato plants. If so, a sophisticated and efficient instrument of resistance breeding could be created. Similar studies are ongoing with Phytophthora infestans. A drug-resistant marker could be used to construct a transformation vector, by which virulent strains could be 


\section{J. C. ZADOKS}

transformed into avirulent ones. With such a vector, the DNA fragments in the fungus determining virulence could be identified and isolated, sequenced, and further manipulated. In this way, pathogenicity could be characterized in molecular terms.

\section{References}

Bollen, G. J., 1974. Fungal recolonization of heat-treated glasshouse soils. Agro-Ecosystems 1: 139-155.

Bollen, G. J., 1985. Non-target effects of pesticides on soil-borne pathogens. In: M. Hascoet, H. Schuepp \& E. Steen (Eds.), Comportement et effects secondaires des pesticides dans le sol, p. 11-26. INRA Publ. 31.

Davidse, L. C. \& W. Flach, 1977. Differential binding of methyl benzimidazol-2-yl carbamate to fungal tubulin as a mechanism of resistance to this antimitotic agent in mutant strains of Aspergillus nidulans. Journal of Cell Biology 72: 174-193.

Davidse, L. C., 1986. Benzimidazole fungicides: mechanism of action and biological impact. Annual Review of Phytopathology $24: 43-65$.

Dekker, J., 1985. The fungicide resistance problem: will it grow worse? EPPO Bulletin 15: $337-344$.

Dekker, J. \& S. G. Georgopoulos (Eds.), 1982. Fungicide resistance in crop protection. Pudoc, Wageningen, $265 \mathrm{pp}$.

Frinking, H. D. \& B. Scholte, 1983. Dissemination of mildew spores in a glasshouse. Philosophical Transactions of the Royal Society London B 302: 575-582.

Frinking, H. D., J. L. Harrewijn \& C. F. Geerds, 1985. Factors governing oospore production by Peronospora farinosa f.sp. spinaciae in cotyledons of spinach. Netherlands Journal of Plant Pathology 91: 215-223.

Limonard, T. \& W. Smits, 1985. The perforated soil system, a new method for root research. In: Proceedings 6th North American Conference on Mycorrhizae (Corvallis, 1984): 254. Corvallis, Forest Research Lab.

Oort, A. J. P., 1944. Onderzoekingen over stuifbrand. II. Overgevoeligheid van tarwe voor stuifbrand (Ustilago tritici). Tijdschrift over Planteziekten 50: 73-106.

Rabbinge, R. \& F. H. Rijsdijk, 1984. Epidemiological and crop physiological foundation of EPIPRE. In: E. J. Gallagher (Ed.), Cereal production, p. 227-235. Butterworths, London, 354 pp.

Reinink, K., 1986. Experimental verification and development of EPIPRE, a supervised disease and pest management system for wheat. Netherlands Journal of Plant Pathology 92: 3-14.

Ruissen, M. A., 1982. The development and significance of vesicular-arbuscular mycorrhizas as influenced by agricultural practices. Thesis, Agricultural University, Wageningen, $111 \mathrm{pp}$.

Schepers, H. T. A. M., 1985. Development and persistence of resistance to fungicides in Sphaerotheca fuliginea in cucumbers in the Netherlands. Thesis, Agricultural University, Wageningen, 56 pp.

Tuyl, J. M. van, 1977. Genetics of fungal resistance to systemic fungicides. Mededelingen Landbouwhogeschool, Wageningen 77-2: 1-136.

Waard, M. A. de, 1985. Fungicide synergism and antagonism. In: Fungicides for crop protection, p. 89 95. BCPC Monograph 31 .

Waard, M. A. de, E. M. C. Kipp, N. H. Horn \& J. G. M. van Nistelrooy, 1986. Variation in sensitivity to fungicides which inhibit ergosterol biosynthesis in wheat powdery mildew. Netherlands Journal of Plant Pathology 92: 21-32.

Wit, P. J. G. M. de \& G. Spikman, 1982. Evidence for the occurrence of race and cultivar-specific elicitors of necrosis in intercellular fluids of compatible interactions of Cladosporium fulvum and tomato. Physiological Plant Pathology 21: 1-11.

Wit, P. J. G. M. de, Ans E. Hofman, Grardy C. M. Velthuis \& J. A. Kuć, 1985. Isolation and characterization of an elicitor of necrosis isolated from intercellular fluids of compatible interactions of Cladosporium fulvum (Syn. Fulvia fulvum) and tomato. Plant Physiology 77: 642-647.

Zadoks, J. C., 1974. Teaching botanical epidemiology at the Agricultural University, Wageningen. Netherlands Journal of Plant Pathology 80: 154-164.

Zadoks, J. C., 1984a. EPIPRE, a computer-based scheme for pest and disease control in wheat. In: E. J. Gallagher (Ed.), Cereal production, p. 237-244. Butterworths, London, 354 pp. 
Zadoks, J. C., 1984b. Cost effectiveness of plant protection on a national basis. EPPO Bulletin 14: 325335.

Zadoks, J. C. \& J. Dekker, 1969. Oort en het onderwijs. Netherlands Journal of Plant Pathology. 75: 2226.

Zadoks, J. C. \& L. M. Koster, 1976. A historical survey of botanical epidemiology. A sketch of the development of ideas in ecological phytopathology. Mededelingen Landbouwhogeschool, Wageningen 76-12: $56 \mathrm{pp}$.

Zadoks, J. C. \& R. D. Schein, 1979. Epidemiology and plant disease management. Oxford University Press, New York, 347 pp. 